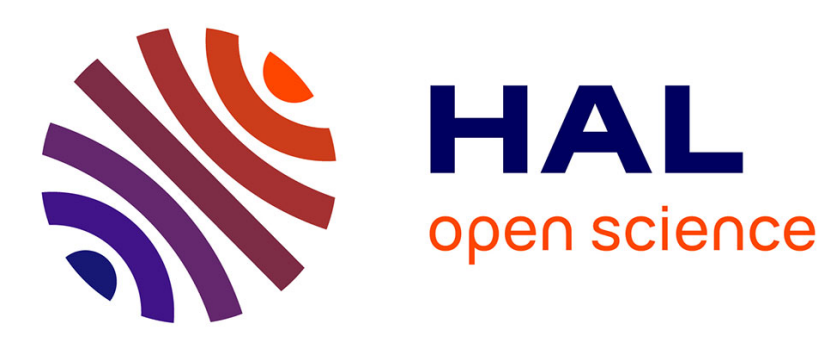

\title{
HYDROGEN SEGREGATION AND DIFFUSION AT GRAIN BOUNDARIES
}

\author{
H. Birnbaum, B. Ladna, A. Kimura
}

\section{To cite this version:}

H. Birnbaum, B. Ladna, A. Kimura. HYDROGEN SEGREGATION AND DIFFUSION AT GRAIN BOUNDARIES. Journal de Physique Colloques, 1988, 49 (C5), pp.C5-397-C5-401. 10.1051/jphyscol:1988546 . jpa-00228043

\section{HAL Id: jpa-00228043 https://hal.science/jpa-00228043}

Submitted on 1 Jan 1988

HAL is a multi-disciplinary open access archive for the deposit and dissemination of scientific research documents, whether they are published or not. The documents may come from teaching and research institutions in France or abroad, or from public or private research centers.
L'archive ouverte pluridisciplinaire HAL, est destinée au dépôt et à la diffusion de documents scientifiques de niveau recherche, publiés ou non, émanant des établissements d'enseignement et de recherche français ou étrangers, des laboratoires publics ou privés. 


\title{
HYDROGEN SEGREGATION AND DIFFUSION AT GRAIN BOUNDARIES
}

\author{
H.K. BIRNBAUM, B. LADNA and A. KIMURA \\ Department of Materials Science, University of Illinois at \\ Urbana-Champaign, Urbana, IL 61801, U.S.A.
}

\begin{abstract}
The segregation of hydrogen at grain boundaries in $\mathrm{Ni}$ has been shown to be dependent on the nature of the boundary using SIMS techniques. This contrasts to hydrogen segregation at free surfaces which appears to be less sensitive to the crystallography of the surface. The increased $H$ concentration due to segregation occurs over appreciable distances from the surface or grain boundaries. The diffusivity of $\mathrm{H}$ along grain boundaries has been determined using SIMS techniques and correlated with studies of fracture kinetics.

INTRODUCTION

While segregation and diffusion of hydrogen at surfaces and grain boundaries has been of great interest, the difficulty of hydrogen microanalysis has limited the number of studies carried out. Secondary Ion Mass Spectrometry (SIMS) techniques have shown that segregation of deuterium $\left({ }^{2} \mathrm{H}\right)$ occurs at free surfaces of $f c c$ Ni (1) and bcc Nb-V alloys (2). Greatly enhanced $2 \mathrm{H}$ concentrations occur at distances behind the free surface of the order of $100 \mathrm{~nm}$. This distribution is sensitive to the presence of monolayers of other segregated species such as $S(1)$. In these studies, no great sensitivity of the ${ }^{2} \mathrm{H}$ segregation on the crystallography of the surface was noted. Segregation of $2 \mathrm{H}$ at uncharacterized grain boundaries in $\mathrm{Ni}$ was observed (1) but extensive subsequent studies have shown that this segregation is very sensitive to the crystallography of the grain boundaries. Diffusion of hydrogen along grain boundaries has usually been assumed to be faster than in the lattice but no measurements of this parameter have been available. A previous SIMS experiment showed qualitatively that permeation occurred preferentially along grain boundaries (3) but attempts to quantitatively measure this effect were unsuccessful (4).
\end{abstract}

\section{EXPERIMENTAL PROCEDURES}

Two principal techniques were used in the present studies; $\operatorname{SIMS}(1,2,5)$ and fracture kinetics. SIMS measurements were carried out at $140 \mathrm{~K}$ using a $17 \mathrm{keV} \mathrm{Cs}^{+}$ ion beam on Ni bicrystal specimens grown from $99.999 \%$ pure Ni which were electrolytically charged with $2 \mathrm{H}$. Measurements were carried out on symmetric tilt grain boundaries having a $\langle 110\rangle$ rotation axis. These crystals were prepared by $\mathrm{Dr}$. M.B. Hintz (6) to whom we wish to express our appreciation. Measurements will be reported for $39^{\circ}(\Sigma=9)$ and for $129^{\circ}(\Sigma=11)$ grain boundaries. The $39^{\circ}$ boundary corresponds to a relatively high energy and the $129^{\circ}$ boundary to a low energy boundary $(7,8)$. Auger electron spectroscopic analysis of the $39^{\circ}$ boundary which was fractured after hydrogen charging showed a fractional grain boundary surface coverage of 0.02 . The low energy $129^{\circ}$ boundary could not be fractured even after hydrogen charging. 
Fracture kinetics were used to study the diffusion of hydrogen along grain boundaries in polycrystalline nickel specimens $(9,10)$. Cylindrical specimens of high purity $\mathrm{Ni}$ (99.999\%), Ni-C, or $\mathrm{Ni}-\mathrm{S}$ alloys were electrolytically charged with $1_{\mathrm{H}}$ at various temperatures followed by tensile fracture at $77 \mathrm{~K}$. Intergranular fracture in the outer annulus delineated the extent to which $\mathrm{H}$ had diffused along the grain boundaries.

\section{EXPERIMENTAL RESULTS AND DISCUSSION}

\section{SIMS MEASUREMENTS}

The electrolytic charging conditions were chosen to form a deuteride at the surface of the nickel bicrystals to provide a reference composition for the grain boundary diffusion. Charging with $2 \mathrm{H}$ was carried out at $295 \mathrm{~K}$ and the diffusion profiles were probed along the tilt axis direction, the $\langle 110\rangle$. Typical concentration profiles for cathodic current densities of $20 \mathrm{ma} \mathrm{cm}-2$ are shown.in Fig. 1 where the deuteride layer thickness varied between 1 and 3.5 micrometers. This variation in the thickness of the deuteride layer reflected differences in the $2 \mathrm{H}$ fugacities at different parts of the surface. The $2 \mathrm{H} / \mathrm{Ni}$ ratio is constant at about 0.7 in the deuteride and the ratio decreased to a value of $10^{-3}$ to $7 \times 10^{-3}$ in the solid solution adjacent to the deuteride as expected from the phase diagram.

Analyses of $2 \mathrm{H}$ at the grain boundaries were performed by step scanning across the boundaries (with a lateral resolution of 2 micrometers) with the typical results shown in Figs. 2 and 3 (for details see reference 11). The initial repeated line scans show a uniform ${ }^{2} \mathbf{H}$ concentration in the deuteride layer in the two adjacent grains and the grain boundary. Below the deuteride layer the $2_{H}$ concentration decreased by about two orders of magnitude which characterized the concentration in the solid solution. (Scans performed through the deuteride-solid solution interface show large variations along the scan, eg. scan 7 in Fig. 3). For the $39^{\circ}$ grain boundary peaks in the ${ }^{2} \mathrm{H}$ concentration were observed in the solid solution at the positions of the grain boundary (Fig. 2). No enhanced $2 \mathrm{H}$ concentrations were seen for the $129^{\circ}$ grain boundary (Fig. 3).

The dependence of the deuteride thickness on the charging time at $295 \mathrm{~K}$ gives a value of the ${ }^{2} \mathrm{H}$ diffusivity in the $\mathrm{Ni}$ deuteride of $3 \times 10^{-12} \mathrm{~cm}^{2} \mathrm{~s}^{-1}$. This value is about two orders of magnitude lower than the diffusivity in the solid solution (4). The greater depth of penetration of the $2 \mathrm{H}$ along the $39^{\circ}$ grain boundary is the result of enhanced diffusivity along the grain boundary compared to the lattice. The lack of enhanced penetration of the $2 \mathrm{H}$ along the $129^{\circ}$ grain boundary indicates that in this case the diffusivity is less than or equal to the lattice diffusivity. An estimate of the ${ }^{2} \mathrm{H}$ diffusivity along the $39^{\circ}$ boundary may be obtained from the measured concentration profiles using the grain boundary diffusivity analysis presented by LeClaire (12). A constant source concentration is provided by the deuteride layer with the origin of the diffusivity being at the solid solution-deuteride interface. The data fit the $x^{6 / 5}$ dependence on distance very well (11) and yield values for $s \delta D_{g b}$ of $3-6 \times 10^{-22} \mathrm{~m}^{3} \mathrm{~s}^{-1}$ ( $\mathrm{s}$ is the segregation factor, $\delta$, is the grain boundary "width", and $\mathrm{D}_{\mathrm{gb}}$ is the grain boundary diffusivity). Assuming a value for $\delta$ of $1 \mathrm{~nm}$ and for $\mathrm{s}$ of $1^{1}$ leads to $a \mathrm{D}_{\mathrm{gb}}$ of $3-6 \times 10^{-13} \mathrm{~m}^{2} \mathrm{~s}^{-1}$ for the $39^{\circ}$ grain boundary. This value may be compared to a value for $2 \mathrm{H}$ diffusivity in the lattice of $3.6 \times 10^{-14}$ (4). The diffusivity of $2 \mathrm{H}$ in Ni at $295 \mathrm{~K}$ is enhanced by a factor of between 8 to 17 for the high energy $39^{\circ}$ grain boundary and no enhancement is seen for the low energy $129^{\circ}$ grain boundary.

\section{FRACTURE KINETICS MEASUREMENTS}

Hydrogen induced intergranular fracture of $\mathrm{Ni}$ at $77 \mathrm{~K}$ has been shown to result from the attainment of a critical hydrogen concentration at the grain boundaries $(13,14)$ the value of which depends on the presence of other impurity species $(15,16)$. While these critical concentrations are not known exactly (13), the ductile to brittle transition as the grain boundary hydrogen concentration increases can be used to measure the diffusivity of hydrogen along the grain boundaries in a polycrystalline specimen. 
Typical results for high purity $\mathrm{Ni}$ are shown in Fig. 4 where the "Grain Boundary Fracture Ratio", ie. the ratio of the intergranular fracture area to the total fracture area is shown as a function of cathodic charging time and temperature. The transition between the outer annulus of intergranular fracture and the inner ductile fracture area was very sharp with the transition often occurring within a single grain boundary. The broken curves on Fig. 4 show the calculated behaivor assuming lattice diffusion as the process which transports $H$ from the surface. As shown, the depth of embrittlement is much greater than can be accounted for by lattice diffusion. A diffusion limited model can be fitted to the data assuming grain boundary diffusion as the transport mechanism (10) with the results shown in Table $I$.

Table I GRAIN BOUNDARY DIFFUSIVITY

TEMPERATURE

314

295

274

$$
\begin{gathered}
\begin{array}{c}
\text { LATTICE DIFF. } \\
\left(\mathrm{m}^{2} \mathrm{~s}^{-1}\right)
\end{array} \\
1.35 \times 10^{-13} \\
5.11 \times 10^{-14} \\
1.49 \times 10^{-14}
\end{gathered}
$$

$$
\begin{aligned}
& \text { GRAIN BD. DIFF. } \\
& \left(\mathrm{m}^{2} \mathrm{~s}^{-1}\right) \\
& 2.8 \times 10^{-13} \\
& 1.1 \times 10^{-13} \\
& 3.4 \times 10^{-14}
\end{aligned}
$$

The value for $\mathrm{D}_{\mathrm{gb}}$ at $295 \mathrm{~K}$ is in good agreement with the value obtained from the SIMS analysis. The activation enthalpy $\left(\mathrm{H}_{\mathrm{gb}}\right)$ obtained for the grain boundary diffusion of $\mathrm{H}$ is $36.1 \mathrm{~kJ}$ mole and the ratio to the lattice diffusion enthalpy is $\mathrm{H}_{\mathrm{gb}} / \mathrm{H}_{1}=0.92$.

Similar results and analyses were obtained for $\mathrm{Ni}-\mathrm{C}$ and $\mathrm{Ni}-\mathrm{S}$ alloys (10) under conditions where the $C$ and $S$ were segregated to the grain boundaries. These results are summarized in Fig. 5 and in Fig. 6 which shows the temperature dependence of the time to achieve GBFR=0.5 for pure $\mathrm{Ni}$ and segregated $\mathrm{Ni}-\mathrm{C}$ and $\mathrm{Ni}-\mathrm{S}$ alloys. It is seen that $C$ has the effect of decreasing the rate of embrittlemeht while $S$ increases the embrittlement rates. Interpretation of these experiments in terms of grain boundary diffusion parameters (10) gives the results shown in Table II.

Table II SUMMARY OF THE H GRAIN BOUNDARY DIFFUSIVITIES

$\begin{array}{lccc}\text { ALLOY } & \begin{array}{c}\text { ENTHALPY } \\ (\mathrm{kJ} \mathrm{mole}\end{array} & \mathrm{H}_{\mathrm{gb}} / \mathrm{H}_{1} & \mathrm{H}_{\mathrm{gb}} / \mathrm{H}_{\mathrm{gb}} \text { (pure Ni) } \\ \text { pure Ni (lattice) } & 39.2 & & \\ \text { pure Ni (gr. bd.) } & 36.1 & 0.92 & \\ \mathrm{Ni}-\mathrm{C} & 40.5 & 1.03 & 1.1 \\ \mathrm{Ni}-\mathrm{S} & 43.9 & 1.1 & 1.2\end{array}$

The pre-exponential terms for the grain boundary diffusivities of the $\mathrm{Ni}-\mathrm{C}$ and $\mathrm{Ni}-\mathrm{S}$ alloys cannot be obtained without knowledge of the effects of segregated $\mathrm{C}$ and $\mathrm{S}$ on the critical $\mathbf{H}$ concentration for intergranular fracture.

\section{ACKNOWLEDGEMENTS}

This work was supported by the National Science Foundation grant DMR 86-05955. We would like to acknowledge use of the facilities of the Center for the Microanalysis of Materials at the Materials Research Laboratory which is partially supported by the Department of Energy.

\section{REFERENCES}

(1) H. Fukushima and H.K. Birnbaum, Acta Metall., 32, 85 (1984).

(2) B. Ladna and H.K. Birnbaum, Acta Metall. 34, 899 (1986).

(3) T. Tsuru and R.M. Latanision, Scripta Metal1. 16, 575 (1982).

(4) J. Volk1 and G. Alefeld, "Hydrogen in Metals I" eds. G. Alefeld and :J. Volk1, Springer-Verlag Press, Berlin (1978) p. 321.

(5) H.K. Birnbaum, H. Fukushima, and J. Baker, "Advanced Techniques for Characterizing Hydrogen in Metals" eds. N.F. Fiore and B.Y. Berkowitz, AIME, 
Warrendale, PA (1982) p. 149.

(6) W. Gust, M.B. Hintz, A. Lodding, H. Odelius, B. Prede1, Acta Metall. 30, 75 (1982).

(7) G. Hasson and C. Goux, Scripta Metall. 5, 889 (1971).

(8) G. Herrmann, H. Sautter, G. Baro, and H. Gleiter, "Grain Boundaries In Engineering Materials" eds. J.L. Walter, H.J. Westbrook, D.A.. Woodford, Claitor's Pub., Baton Rouge (1974) p. 43.

(9) H. Kimura and H.K. Birnbaum, Scripta Metal1. 21, 219 (1987).

(10) H. Kimura and H.K. Birnbaum, Acta Metall. In press.

(11) B. Ladna and H.K. Birnbaum, Acta Metall. In press.

(12) A.D. Leclaire, British Jn1. Appl. Phys., 14, 351 (1963).

(13) D. Lassila and H.K. Birnbaum, Acta Metall. 34, 1237 (1986).

(14) S.M. Breummer, R.H. Jones, M.T. Thomas, and D.R. Baer, Scripta Metall. 14, 1233 $(1980)$.

(15) R.H. Jones, S.M. Bruemmer, M.T. Thomas, and D.R. Baer, Metall. Trans. 14A, 1729 (1980).

(16) D. Lassila and H.K. Birnbaum, Acta Metal1. 34, 1237 (1986).

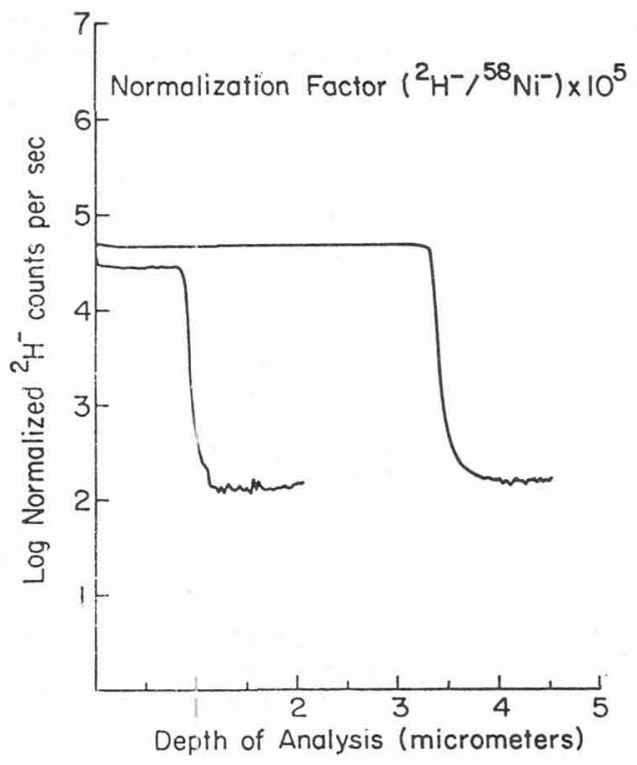

Fig. 1 Normalized profiles of $2 \mathrm{H} . \mathrm{Ni}$ crystals cathodically charged at $295 \mathrm{~K}$ for $3 \mathrm{~h}$ at $2 \mathrm{ma} \mathrm{cm}-2$. The curves are indicative of repeated measurements at different points on the surface.

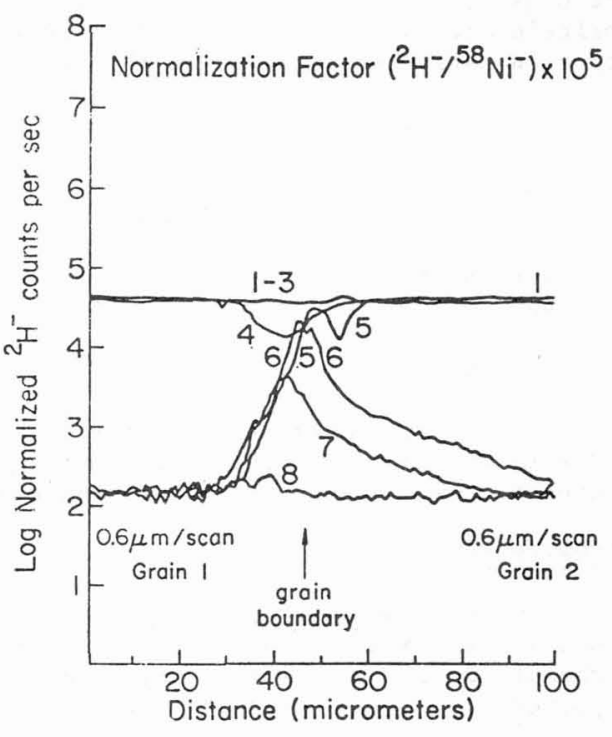

Fig. 2 Normalized line scans of $2_{\mathrm{H}}$ across the $39^{\circ}\langle 110\rangle$ tilt boundary in cathodically charged $\mathrm{Ni}$. The numbers indicate the sequence of line scans. 


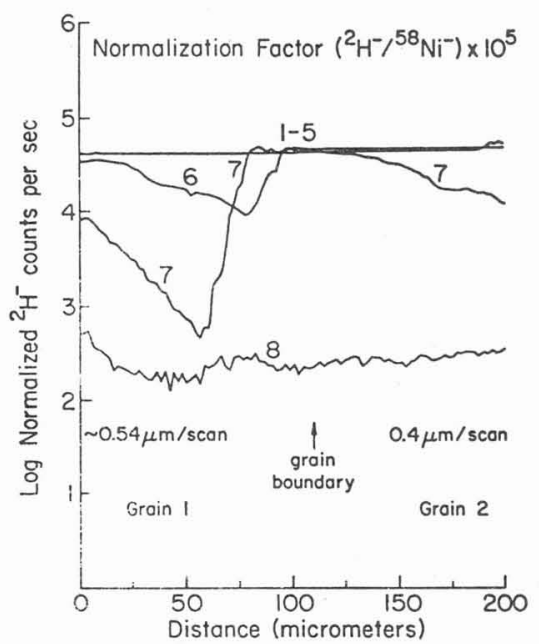

Fig. 3 Normalized line scans of ${ }^{2} \mathrm{H}$ across the $129^{\circ}\langle 110\rangle$ tilt boundary in cathodically charged bicrystals of Ni. The numbers indicate the sequence of line scans.

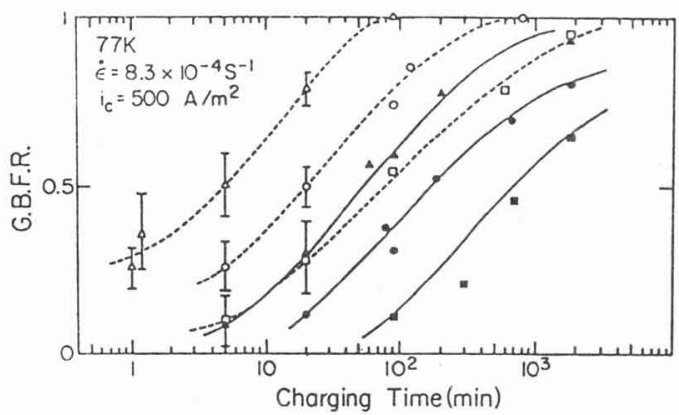

Fig. 5 Grain boundary fracture ratio as a funciton of cathodic charging time and temperature for $\mathrm{Ni}-\mathrm{C}$ (solid points) and $\mathrm{Ni}-\mathrm{S}$ (open points). $\begin{array}{lll}273 \mathrm{~K} ; & 293 \mathrm{~K} ; & 317 \mathrm{~K} \text {; } \\ 273 \mathrm{~K} ; & 296 \mathrm{~K} ; & 317 \mathrm{~K} \text {. }\end{array}$

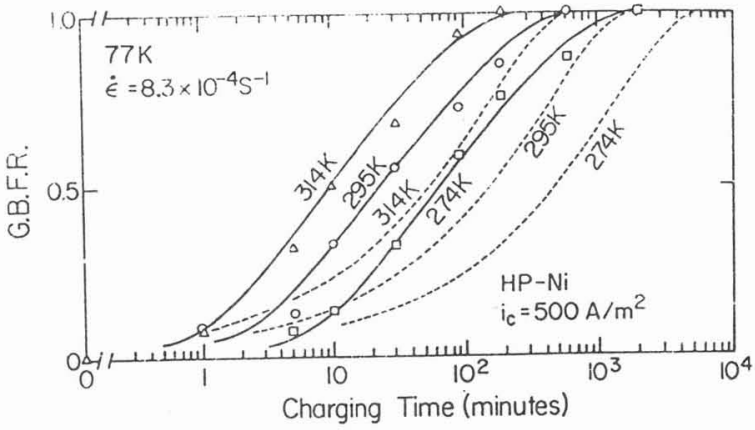

Fig. 4 Grain boundary fracture ratio as a function of cathodic charging time and temperature for pure $\mathrm{Ni}$. The broken curves are calculated values based on lattice diffusion.

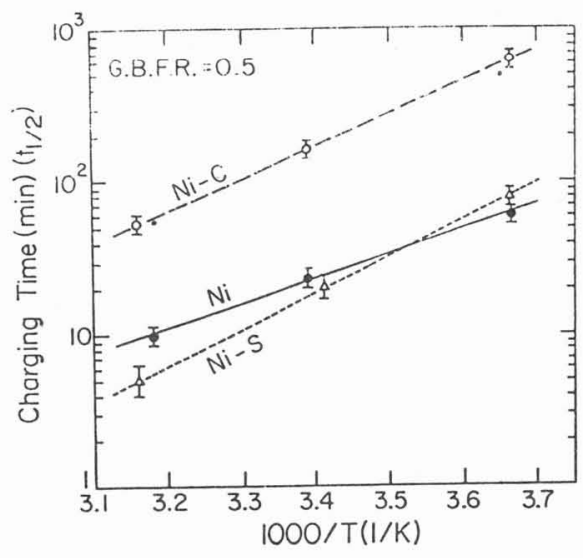

Fig. 6 Cathodic charging times to attain a $G B F R=0.5$ vs temperature for pure $\mathrm{Ni}$ ; $\mathrm{Ni}-\mathrm{C}$ ; and $\mathrm{Ni}-\mathrm{S}$ 